\title{
Modeling of the Socio-Economic Potential of the Siberian Regions with Consideration for their Economic-Geographical Position in the National Economic System of the Russian Federation
}

\author{
A.V. Myadzelets* \\ V.B. Sochava Institute of Geography SB RAS, Irkutsk
}

\begin{abstract}
This paper is concerned with the methods of mathematical modeling of the socioeconomic development of regions. The objective of this study is to analyze and assess the socioeconomic potential of the territory having regard to its individual socio-economic and economicgeographical characteristics. The territory's individual characteristics, in turn, are treated as invariant conditions of its development. The study territory includes regions and federal districts of the Russian Federation.

An assessment of the regions' development potential is made from the perspective of analyzing their current socio-economic situation for the time interval 1999-2002 taken from official statistical handbooks. To accomplish this, a special-purpose mathematical model is developed in the form of a hierarchical fractal indicative function relating the generalized indicator characterizing the regions' development potential, or the "indicated" (that which is indicated versus indicator), to the particular socio-economic characteristics of the territory, or the development indicators of the local economy, via the model coefficients which is termed regulators.

As a result, the economic-mathematical model is generated in the form of an indicative function characterizing the current socio-economic situation of the regions and federal districts of Russia on different levels of economic organization (from local and regional to national). It reflects appropriately and dramatically the specific character of the region's socio-economic potential by the example of the connection of investments with the volumes of production. The model permits the position of the regions and districts to be identified in the system of inter-regional and national socio-economic links and economic-geographical conditions of development. The results derived from modeling the socio-economic development potential of Russia's regions have been used to construct the control surface of the country's economy characterizing the changes in the
\end{abstract}

*E-mail: anastasia@irigs.irk.ru 
development potential of the federal districts toward its decrease.

Key words: socio-economic development, potential, investments, volume of production, invariant economic-geographical conditions of development, indicator, regulator, the indicated, indicative function, functional complex

AMS subject classification: 91D20

\section{Introduction}

The fact that socio-economic research throughout Siberia's territory is a currently central issue from the perspective of effective planning and forecasting of a further development of the Siberian regions in particular and the Russian Federation (RF) in general is beyond question. The close interconnection of different-level administrative territories (municipal formations, regions, and countries) through an array of relations implies that research of this kind must be done not only on the local and regional level but also within the framework of the national and world economic system. This paper is concerned with one of the areas of socio-economic research involving assessment and mathematical modeling of the socio-economic potential of a territory. The objective of this study is to analyze the socio-economic potential of a region having regard to its individual socio-economic and economic-geographical characteristics. The study territory includes the regions of the RF; the regions of the Siberian Federal District are discussed more elaborately.

To achieve the goal, the author addresses the following issues: developing the mathematical methods for analyzing the socio-economic potential of a territory in different local and regional settings, determining the hierarchical structure of the national economic system of the RF, identifying in this structure the characteristics of the economic-geographical position of Siberia's regions, and determining the socio-economic potential of the regions under consideration using the mathematical models that have been developed. The results obtained in this study provide a basis for further forecasting and planning of the development of territories in different economic and geographical conditions.

\subsection{Background and description of the problem}

The subject of this investigation focuses on the socio-economic potential of a territory. It is known that it is an important factor in developing territorial planning programs. In the scientific economic and economic-geographical literature, the notion of the potential of a system, in particular, the potential of the socio-economic or territorial system, is treated ambiguously. As a consequence, in the substantive interpretation of the term "potential" in general and "socio-economic potential" in particular there arise serious differences.

The physical and the economic approaches are recognized in the interpretation of the potential [1]. The economic approach involves assessing the potential in monetary form, and the physical 
approach implies appraising the potential in terms of such physical categories as energy, matter, entropy, and resource.

The economic approach is most customarily used, where the potential is generally considered to mean the possibilities, abilities and latent, unrealized reserves of an object under study which, once the surrounding conditions are changed, can switch from a possibility over to a reality [20].

Traditionally, by the economic potential is meant an aggregate ability of a country's economy as an economic system (or any other administrative territory), its sectors, enterprises, and businesses to carry out the production-economic activities, turn out products, commodities, and services satisfy the needs of the population and social requirements, and to ensure a further development of production and consumption. A country's economic potential is determined by its natural resources, means of production, labor and scientific and technological potential, and by its accumulated national wealth [15]. Furthermore, economically, the potential represents a set of economic relations between subjects of the socio-economic system as regards assessment, appropriation, utilization and development of resources and information [1].

The socio-economic potential is closely allied to the economic potential, but, essentially, it is somewhat broader because of introducing an additional, social, component. It provides a basis for the creation of the gross product (municipal, regional, national, etc.), and this basis consists of a number of main units (such as treasury, funds of the financial-crediting system, the financialeconomic potential of enterprises and organizations, financial means of the population, and external loans and investments as the sum of externally borrowed financial resources) and includes a system of socio-economic and normative-legal relations whereby the process of ensuring the socio-economic development of the territory is realized in accordance with its status. The basis for generation of such a potential is provided by a set of production-raw materials and personnel resources of the territory [3].

The potential cannot exist without a definition of the goal of its utilization, because, while on the subject of a given potential, what requires reserves and possibilities is always implied, namely, the attainment of some end result [20]. The socio-economic potential of a territory as a reserve is necessary for the functioning of its economy; it is aimed at the achievement of strategic and tactical targets of socio-economic development of a territory [3]. In this sense the socioeconomic potential forms a foundation for a region's development, and its assessment, analysis and modeling are necessary for the drawing-up of objective, scientifically grounded plans and forecasts of development of a municipal entity, a region or the country as a whole.

This paper investigates the socio-economic potential of the territory (hereinafter referred to as the potential) from its current socio-economic situation which is an objective reflection of the past, present and future. Usually, it is assessed using special-purpose qualitative and quantitative indices, such as the population size, income, the volumes of production, the investment climate, the political situation, and others. In addition to the potential, a current situation characterizes also the position of a given territory in the system of socio-economic relations, ties and conditions of development on different levels of organization, from local to global. The elaboration of interdisciplinary research directions at the junction of mathematics, economics and geography opens up new avenues for the description of the socio-economic situation and the position of a territory in the form of a flexible economic-mathematical model. This model furnishes a means of determining 
the "coordinates" of a territory in the system of socio-economic links on different levels of organization (local, regional, national, etc.), taking into consideration their possible changes, assessing the optimality and balance of development, modeling the socio-economic situations and potential of a territory according to transformation of initial external and internal conditions of development, etc.

Models for assessment and subsequent analysis of a territory's socio-economic potential must take integrally into consideration the individual characteristic properties inherent in a particular region. Typically such a "local" approach is not foreseen in standard methods of data analysis. Hence socio-economic research needs elaboration of new expeditious tools for systemic and comparative analysis, modeling and forecasting of socio-economic processes and phenomena in the changing spatio-temporal conditions. Interdisciplinary approach is called for, which would be implemented, in particular, at the junction of geographical, mathematical and conceptual sciences. It is this approach which would make it possible to cope with the information shortage problem, take into consideration the local characteristics of a territory under investigation, and to identify its merits and demerits with respect to other locations.

\section{Model and methods}

Analysis and assessment of the socio-economic potential of a territory is a necessary stage in planning and forecasting its sustainable (balanced) development, and the development of specialpurpose mathematical models is an integral element of the political and economic activities of most countries.

By modeling of socio-economic processes is understood the system of mathematical expressions which involves variable economic and socio-economic quantities and parameters. The quantities include statistical socio-economic indices, such as the population size, production outputs, investments, etc. The parameters, in turn, characterize quantitative connections between quantities; their variable values must be inferred by analyzing a system of equations producing the mathematical model for the socio-economic process. The models are divided into statistical and dynamical. In statistical models, all indices are referenced to a definite instant of time, and the connection between indices of different period of time is not considered. In dynamical models, the development of the economic process is examined across time, and the temporal connection of the economic indices is determined. A variety of the model is also represented by the solution to the problem of optimal functioning of a socio-economic object, or the determination of the optimality criterion (goal function) of the activity of a given object. A mathematical modeling in the field of economic and socio-economic research is usually undertaken in order to forecast, plan, analyze and manage the socio-economic phenomena, processes and objects [4].

Modeling of economic and socio-economic processes has a long history and is closely associated with the advancement of other sciences (mathematics, geography, economics, demography, etc.), which lends credence to the interdisciplanary nature of socio-economic research.

The time interval of the late 19th - early 20th century witnessed the development and formulation of equilibrium models in economics (L. Walras) which, as early as the mid-20th century, 
generated a whole field of General Equilibrium Theory. At about the same time (the early 20th century), socio-economic analysis began to employ simple Keynesian-type models (J. Keynes) related to the theory of economic growth. Their simplicity is explained by the fact that they contained a small number of variables and equations. It was followed by an active development of econometric methods with increasingly sophisticated models along two "arbitrary" directions: planning and forecasting. The economic mechanism in them is described in terms of a number of selected factors.

In regional economic analysis, the first half and mid-20th century saw the emergence of widely known models of the theory of central places, the theory of displacements, and other theories which were developed and further elaborated by A. Weber, J.H. von Thnen, W. Christaller, A. Lsch, D. Bough, B. Berry and W. Garrison, R. Morill, and others.

In the 1970s there emerged one further variety of models which can be combined into a group of ecologo-economic models. The originators and pioneers of this line of inquiry were J. Forrester [16], D. Meadows [21], and V.V. Leontiev [11]. J. Forrester developed the system dynamics, and V.V. Leontiev devised a subsequently widely used intersectoral balance method (input-output analysis). The first variant of the input-output model took into consideration only the economic component, yet it was expanded through the ecological factor introduced by V. Leontiev in collaboration with D. Ford [11]. Subsequently, the input-output method evolved into a major area which was arbitrarily called "Leontiev-type models" within which one can find a large number of examples with varieties of socio-economic models of this kind [2,13]. A further variant of such models is the model of activity analysis of production (T.Ch. Koopmans). These models, all are linear, but the activity analysis method contains more degrees of freedom when compared with a conventional input-output model, and has natural capabilities for optimization.

Equally widely known in economics are the linear programming models such as the simplex method invented by G.B. Danzig, the economic growth model due to J. von Neumann, the transport models, the L.V. Kantorovich models, and others. In addition to the aforementioned models, in economics there are widely recognized production functions [2], the first and classic example of which is the Kobb-Douglas production function. Research in economics is also elaborating effective models of nonlinear programming, the decomposition method, and others.

One more group of models in socio-economic investigations has been generated since the 1970s-1980s in publications on modeling of the regional economy, such as the well-known "Region" model due to V.I. Gurman [12, 14]; this model is useful for forecasting changes in natural environment under the influence of the economic activities, comparing alternatives as regards the economic effectiveness of a region's development in terms of the influence on natural environment. Also it works for optimizing the territorial development programs according to criteria linking the economic effectiveness with the state of natural environment.

Aside from traditional methods of modeling economic processes, new theories and methods are being developed, such as the theory of rational behavior in uncertainty conditions, information theory, general system theory, theory of groups, game theory, and others. These approaches have not yet received large-scale, constant practical implementation, but the dynamicity of their advancement, scientific and technological progress and the demand of economics for the development of new analysis and assessment methods in view of the large degree of uncertainty of the 
development factors require that science should pay more attention to alternative methods of modeling socio-economic situations. The approach suggested in this paper is also one of the alternative assessment methods in the field of socio-economic research.

This technique for assessing and modeling the socio-economic potential of the territory is being developed as a comprehensive cross-disciplinary scientifically grounded theory forming part of the general direction in the field of polysystem modeling of natural and anthropogenic processes. The purpose of this technique is to solve a number of subjective and objective methodological problems which necessarily arise in the socio-economic analysis, planning and forecasting under current market conditions like a lack of data, uncertainty, changing conditions from place to place (that is localization of the situation), individual characteristic features, etc. This method forms a basis for generating the mathematical technology procedures of problem-solving which make it possible to use fundamental mathematical principles in order to reveal the hidden regularities. It is a knowledge that can be extended to any domain of science; therefore, mathematical technologies are aimed at advancing an integral knowledge of objects and their properties and are oriented to generate statistical data processing methods. The model under development is a synthesis of mathematical and statistical methods.

According to the theory of systems of macropotentials [18], any territory represents a geographical object (an economic-geographical system) that is described by a set of potentialscharacteristics. In this case, the potential is a quantitative natural, social or economic characteristic (parameter) which describes the economic-geographical system as a whole. For instance, potential characteristics are represented by areas of lands, reserves of resources, population size, production outputs, tying-up of capital (investments), financial flows, income of the population, etc. which reflect in an integral manner the existing economic and social situation on the territory.

It is customary to recognize particular and generalized potentials. Generalized potentials are a function of particular potentials and reflect integrally the interconnections of all natural, social and economic characteristics of the territory as an integral system; for instance, they are investments or gross production outputs of an administrative district. The generalized potential is a summarizing parameter characterizing the effectiveness of functioning of the territorial system.

Interpretation of the approaches of the theory of macropotentials for the purposes of socioeconomic and economic-geographical research uses the theory of indicative planning. It is recommendatory planning and forecasting of the socio-economic development in uncertainty conditions of the market economy oriented to the indices specified which are called the social and economic indicators of development $[6,10]$. The indicator represents an integral index that quantifies the qualitative characteristics of a particular process or state. This indicator is used to determine the parameters of the boundaries within which the system will be stably functioning and developing. The indicators are divided into the main (basic) indicating (indicators proper: natural, social and economic particular potential characteristics of the territory) and indicated (the indicated - resulting generalized potentials) variables. The characteristic properties of the response of an indicated variable (for instance, of a generalized function of state of the system) to a change of the value of a corresponding indicator is determined by controlled regulators. They are special mechanisms for sustaining an optimal functioning of the territory whereby the influence on the object or its control is realized. 
The basis for assessment and modeling of the potential of a region, as pointed out above, is the analysis of the socio-economic situation. To describe the socio-economic situation of a territory uses an econometric mathematical model of the form

$$
I=F(x),
$$

which is said to be the indicative function: statistical data locally determine the connection of the output characteristic (the indicated) $I$ of the object with the set of influencing factors (indicators) $x=\left\{x_{i}\right\}, i=1, \ldots, n$. One of the forms of local representation of any analytical functions is the tangential Legendre transformation $F(x) \rightarrow \bar{F}(a)$ :

$$
F(x)+\bar{F}(a)=\sum a_{i} x_{i}
$$

where $a=\left\{a_{i}\right\}$ is a set of sensitivity variables $\left(a_{i}=\frac{\partial F}{\partial x_{i}}\right) ; \bar{F}(a)$ is a function of these variables (sensitivity function), conjugated by the transformation (2.2) with the function of importance (assessment or the indicated) $F(x)$. These functions depend only on their variables $a$ and $x$, respectively. In the applications, the sum $D(x, a)=F(x)+\bar{F}(a)=\sum a_{i} x_{i}$ is said to be the action [19], so that the value of $F(x)$ and the sensitivity $\bar{F}(a)$ are mutually complementary with respect to the action $D(x, a)$. When $\bar{F}(a)=0$ the transformation (2.2) is said to be degenerate, which suggests there exist internal connections between the variables $x$. In this case, the action coincides with the importance function, and

$$
F(x)=\sum a_{i} x_{i}
$$

is the Euler equation for first-order homogeneous functions $F(x)$.

The variables $a$ involved in (2.2)-(2.3) have the meaning of regulators of functional connections, determining the directedness and intensity of action of the factors $x$ upon the end result $I$. The action $D(x, a)=\sum a_{i} x_{i}$ is a bilinear function of influence of a set of factors $x$ and of the environment $a$ on $I$. Here, the variables $x$ and $a$ operate simultaneously by complementing each other informationally, so that the tangential representation (2.2) becomes an exact model of the relation $I=F(x)$. Statistically, the values of $a$ are determined by regression analysis methods (regression coefficients) for a small $(N>n)$ local sample.

There is also a possibility for an inverse Legendre transformation $\bar{F}(0) \rightarrow F(x)$, which follows also from the relation (2.2). In this case, a formal system turns out to be closed onto itself. It is not inconceivable, however, that an open development of this system can take place, where the function $\bar{F}(0)$ transforms not to $F(x)$, but to a function of new variables in a similar manner to (2.2):

$$
F_{2}(b)+\bar{F}(a)=\sum a_{i} b_{i}, b=\left\{b_{i}\right\} .
$$

The expression (2.4) implies that the coefficients of equation (2.2) are bilinearly dependent. Upon substituting the value of $\bar{F}(0)$ from (2.4) into (2.2), we obtain

$$
F(x)=\sum a_{i}\left(x_{i}-b_{i}\right)+F_{2}(b)
$$


i.e. a bundle of planes intersecting at the point with coordinates $\left(b, F_{2}(b)\right)$, which is said to be a functional complex. From this, and from the optimality condition $a_{i}=0$ it follows that the extreme value of $F(x)=F_{2}(b)$. In the general case we have $F(x)=-F(0)=F_{2}(b) \neq 0$. In the bundle, the situations vary in the conditions of the action $a$.

Consecutive transformations of $F_{2}(b) \rightarrow F_{3}(c)$ can be continued:

$$
F_{2}(b)+F_{3}(c)=\sum c_{i} b_{i}, c=\left\{c_{i}\right\} .
$$

Hence it follows that $F_{2}(b)$ depends linearly on $b$, i.e. the centers of the bundles lie in the directrix plane with a changing slope $c$. By introducing additional variables $d$, we obtain

$$
F(x)=\sum a_{i}\left(x_{i}-b_{i}\right)+\sum c_{i}\left(b_{i}-d_{i}\right)+F_{4}(d) .
$$

A comparison of this with (2.5) clearly shows that $F_{2}(b)$ represents a bundle of directrixes centered on $\left(d, F_{4}(d)\right)$. Hence it follows that consecutive Legendre transformations give rise analytically and geometrically to multilevel fractal similarity structures which describe exactly any composite function of influencing variables.

Fractal equations of the form (2.7) are an exact expression of the various functional interconnections irrespective of their systemic interpretation. Therein lies the hierarchy of interconnections, influence of the factors and interaction of the processes inherent in the objective reality.

It is assumed that the fractal properties of the indicative model (2.2) make it possible to consistently describe the hierarchical structure of a State's socio-economic space by the following equations: I - the level of the indicative function to which equation (2.2) corresponds; II - the level of the functional complex, the coordinates of the center of which show the local one-type invariant economic-geographical conditions of development of the regions (this corresponds to equation (2.4)); III - the level of the directrix of several functional complexes, i.e. territories connected by a common tendency (direction) of development according to their regional socio-economic potential (see equation (2.6)), and IV - the functional complex of directrixes of territories combined by the more general invariant conditions of development. In this case, it corresponds to several States connected by one type of socio-economic potential (see equation (2.7)), etc.

The data obtained by the fractal equation are analyzed by statistical methods. First we estimate the multiple linear regression coefficients (2.2) for local samples; then we investigate in a similar fashion the correlatedness of the equations of the equations obtained (2.4), and so forth. The objects having correlated coefficients (2.4) are assigned to the same class (to the bundle of dependencies, or congruence). The center of congruence $\left(b, F_{2}(b)\right)$ identifies the type of environment of interaction between objects of this class, and their optimal mode of functioning $F_{2_{0}}(b)=F_{2}(b)$. A deviation $\Delta F_{2}(b)$ from an optimal regime $\left(b, F_{2}(b)\right)$ is considered to be a disturbance of a balanced functioning of the system, which manifests itself as a deviation of the actual value of $F_{2}(b)$ from the optimal value of $F_{2_{0}}(b)\left(\Delta F_{2}(b)=F_{2}(b)-F_{2_{0}}(b)\right)$. Graphically, this implies that the plane of connection (2.2) does not pass through the center of the bundle $\left(b, F_{2}(b)\right)$ but it deflected from it along the axis $I$ by $\Delta F_{2}(b)$. A minimization of this deflection signifies that the plane reverts to the composition of congruence. 
The resulting mathematical relations and transformations add up to give a sequence of procedures of mathematical technology which is extended to the analysis of field data in the form of statistical optimization. This makes it possible to investigate locally, using a limited temporal series of data, the unknown function $I=F(x)$, to represent it as a fractal equation, and to calculate its extreme (optimal) values according to the position (environment) selected.

In this paper, for assessing the socio-economic potential of the territory, we suggest, as the indicated $F$ and the indicators $x$, that the following generalized economic indices should be used: investments $I$ (the indicated of the socio-economic potential), and the gross outputs of production and agriculture (the indicators $x_{1}$ and $x_{2}$, respectively), which are complex-dependent on the other potentials (the area of the territory, the reserves of the resources, the size of population, the level of development of the infrastructure, etc.) involved in the process of economic development of districts under consideration. Then $I$ is a function of the degree of economic development of the territory in the context of its investment attractiveness. Here, the regulators $a_{i}$ have a concrete economic meaning - they are the particular accelerators of development of the economy as regards the industry and agriculture, showing how the level of investments would change with a change in the output of this sector by unity.

The selection of the indicators is based on the fact that investments are a peculiar "temperature" of the activity of political and economic processes within a territorial formation, and a degree of their reliability and efficiency. Socio-economic growth of the system is eventually determined by the inflow of money into the main kinds of production, which is a potential of its self-development. The effectiveness of functioning of the system (the effectiveness of investments in the economy of a territory, for examle, municipal formations or districts, in this case) is determined by the increase in output of the various sectors of the economy in the district. The volume of production, in turn, reflects also the level of living of the population (average income, natural growth and migration, unemployment rate, etc.), and the "working capacity" of the local economy. Estimating calculations of the regulator coefficients in terms of the model of the indicative function confirmed the relationship of particular social development potentials and their influence on the selected generalized integral potentials of territorial development as exemplified by the districts of the Republic of Buryatia [8]. The results of calculations demonstrated dramatically how the social potentials (the total population size, the size of the population employed in the economy, and the average rate of wages) influence the index of overall production in the administrative districts of the Republic of Buryatia on a regional scale and depending on their local conditions of development.

Not only do the economics publications consider the concept of investments to be one of the main indices of the economic activities on the administrative territory; they prove that there is a linkage between investments and the Gross National Product (GNP), see, e.g. Hansen (1959) [17], which is associated with the study of economic cycles and factors influencing business fluctuations in the economy. Investments determine the essence and form of business fluctuations in the economy over time, i.e. business activity is manifested in the movement of the GNP. Gross outputs of industrial and agricultural production eventually constitute the greater part of the country's GNP or of the gross regional product (GRP); consequently, from this point on, it is possible to speak in general of the analysis of the interaction of investments as a generalized potential of the economic activities and economic development with the volumes of industrial and agricultural production as 
development indicator potentials. Besides, an inverse causal relationship is also traceable between the potentials under consideration [17], which is substantiated mathematically [5, 18].

Such connections reflect an investment cycle which is represented in its simplified form by the commutative diagram (Fig.1); the arrows indicate in the general case the material, financial and information flows. The "Local Economy" unit includes natural and labor resources, the size of fixed assets (capitals), work load of enterprises, demand for products, etc.; the "Gross Output" unit reflects overall production both for the industry and agriculture as a whole and for separate sectors of the economy $\left(x_{1}, x_{2}\right)$, and the "Investments" unit contains, accordingly, information on investments in the economy of a territory $(I)$.

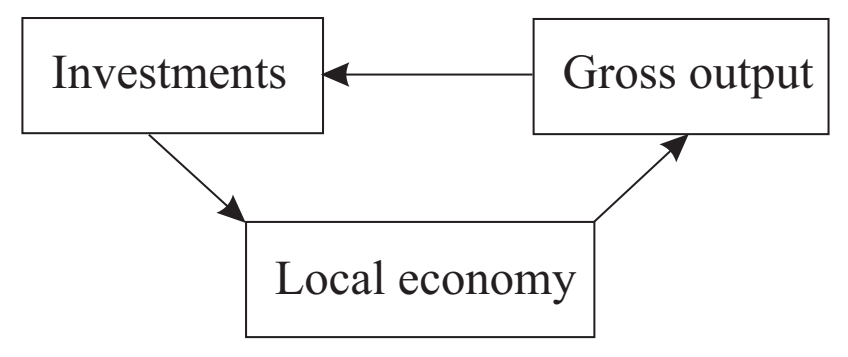

Figure 1: Commutative diagram of investment cycle

The model of the indicative function (2.2), in view of the chosen indicator socio-economic characteristics, was tested for the local level of territorial hierarchy using, as an example, the municipal formations of the Irkutsk region, the Ust-Ordynsky Buryat Autonomous District (AD), and the Republic of Buryatia (Russia). The testing results lent support to the objectivity of the suggested indicative function, and to the selection of the indicator characteristics for assessing the socio-economic situation of the territory $[9,10,20]$ having regard to their economic-geographical location, and for their internal relations. Consequently, this model can be used in further investigation in order to assess and model the socio-economic development potential of other different-level territories, such as the regions of the RF in the national economic system.

Let for the purpose of this investigation the investment potential that reflects the economic component of territory development, be treated as a particular case of a region's socio-economic development potential, because, as was shown above, it takes into account indirectly the social characteristics of the economic situation of the administrative entities as well. It is described by the following indices: $F(x)$ is the level of investments in fixed assets, $x_{1}$ is industrial output, and $x_{2}$ is agricultural output (the data cover the time interval 1999-2002 and are taken from the "Russia's Regions" Handbooks for 2000, 2001, 2002, and 2003); the coefficients $a_{1}, a_{2}$ and $\bar{F}(a)$ are calculated from factual data by the methods of multiple regression analysis. The autonomous districts forming part of Territories (Krais) and regions (Oblasts) are treated as separate administrative entities of the RF. The emphasis is on the regions of the Siberian Federal District (FD): Altai Republic, Republic of Buryatia, Republic of Tyva, Republic of Khakassia, Altai Territory, Krasnoyarsk Territory, Taimyr (Dolgano-Nenetsky) AD, Evenki AD, Irkutsk region, Ust-Ordynsky Buryat $\mathrm{AD}$, Kemerovo region, Novosibirsk region, Omsk region, Tomsk region, Chita region, and Aginsky Buryat AD. 


\section{Results}

Modeling of the socio-economic potential of the Siberian regions was carried out in several consecutive stages according to the model of the indicative function outlined above.

1. Determination of the particular kind of indicative functions of the RF regions by calculating the regulator coefficients based on factual socio-economic data.

2. Modeling of the socio-economic potential of the Siberian regions in the national economic system of the Russian Federation depending on their economic-geographical location. Identification of regional functional complexes within the context of federal districts.

3. Identifying the directrix of socio-economic development of the federal districts of the RF, and generation of a general fractal hierarchical structure of the national economic structure of the RF. Local determination - in this structure - of indicative functions of the Siberian regions and the coordinates of the centers of the functional complexes of the federal districts of the RF.

Stage 1. The particular form of indicative functions of the RF regions was determined by statistical methods in terms of the model $F(x)+\bar{F}(a)=\sum a_{i} x_{i}$ (2.2). In view of the designations of the indicated and indicators introduced here, the model (2.2) takes the form of the equation

$$
I(x)=a_{1} x_{1}+a_{2} x_{2}-\bar{F}(a)
$$

The calculated coefficients of the indicative functions for the regions of the Siberian FD are presented in Table 1. The coefficients $a_{1}$, and $a_{2}$ of the indicative functions of the regions make it possible to judge the character of the influence of the indicator characteristics of the function (gross output of industrial and agricultural production) on the investment potential of a given territory. The sign of the coefficient enables one to draw the conclusion about the positive or negative influence of the corresponding indicator on the generalized economic development potential of a region, while the numerical value of the coefficient (in magnitude) shows how strongly this indicator influences the indicated: the larger is the value of the coefficient, the more strongly a corresponding indicator influences (positively or negatively) on the investment climate in the region.

It is evident from the coefficients in Table 1 that in Krasnoyarsk Territory and in the UstOrdynsky Buryat AD, the investment potential is negatively affected by the indicator of industrial production, while in Altai territory, the Irkutsk, Kemerovo, Omsk, Tomsk and Chita regions, and in the Evenki AD, the negative influence comes from the indicator of agricultural production, and in the Evenki AD this influence is significantly clearly pronounced $\left(a_{2}=-24.5186\right)$. Analysis of the value of the coefficients of the indicative functions of the regions in the Siberian FD suggests the conclusion that the most favorable conditions for the realization of industrial potential as regards investments correspond to the Evenki and Taimyr AD which are considered without regard to the economy of Krasnoyarsk territory, which seems to be explained by the development of the primary sector on this territory. As regards the agricultural potential for the economic development of the territory, strange though it may seem, the most favorable conditions correspond also to the Taimyr $\operatorname{AD}\left(a_{2}=29.0210\right)$, with Krasnoyarsk Territory lagging considerably behind it $\left(a_{2}=3.0836\right)$. For the four-year period under investigation the other regions do not have any pronounced agricultural potential, because the coefficients of the indicative function with the variable describing agricultural production are less than unity. Obviously this is attributable to the general agricultural 
crisis in this country, and to the absence of a clearly defined governmental policy and strategy of development of the agricultural sector.

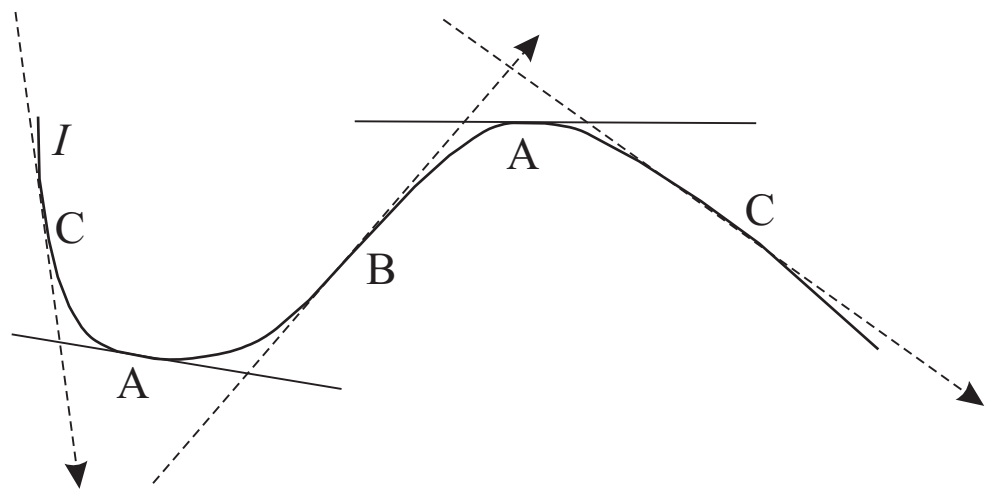

Figure 2: Analysis of the general tendency of local economic development $I$ - indicative function, $\mathrm{A}$ - region of fundamental change in the economy $(-0.9<\mathrm{r}<0.9), \mathrm{B}-$ region of upswing $(\mathrm{r}>0.9)$, $\mathrm{C}-$ region of recession $(\mathrm{r}<-0.9)$

By calculating the correlation coefficients of the indicative functions of the territory at this stage of analysis, it is possible to appraise the general tendency for development of the local economy. For the Siberian region it was shown (see Table 1) that the lowest correlation coefficients (less than 0.9) correspond to the Republic of Khakassia, Chita region, Taimyr AD, and Ust-Ordynsky Buryat AD. This suggests that at the given period the economy of these regions does not exhibit any definite tendency for development (positive or negative) and resides at a certain breaking point to be followed by economic growth or recession (see Fig. 2).

Stage 2. Let us consider in greater detail the modeling scheme for the socio-economic potential on the regional level for the Siberian FD. Mathematically, this means to determine optimal with respect to the correlation coefficient groups, or functional complexes, within the framework of the existing administrative-territorial division of the RF into regions and districts. The initial correlation coefficient $(r=0.16)$ shows that in this group there are regions which are likely to refer to a different type of economic-geographical conditions of development. A subsequent analysis revealed that the congruent connection of the indicative functions in the complex of the Siberian FD is influenced dramatically by the functions of the Taimyr and Evenki AD. If these administrative units are excluded from this functional complex, then the correlation coefficient is 0.89 . Hence it can be concluded that they are evolving in different economic-geographical conditions.

For modeling the regional functional complex of the Siberian FD we examine, additionally, the neighboring Urals and Far-Eastern FD.

The Urals FD comprises the Kurgan, Sverdlovsk, Chelyabinsk and Tyumen regions, including the Khanty-Mansi and Yamalo-Nenetsky AD, and their correlation coefficient is 0.79. Since the Tyumen region, with the autonomous districts incorporated in it, had formed part of the WesternSiberian region previously, we assign the Tyumen region to the complex of the Siberian FD (let it be referred to by the Siberian model group), and we combine the Khanty-Mansi and YamaloNenetsky AD via a functional congruent connection with the Taimyr and Evenki AD that were 
excluded from the complex of the Siberian AD. Then for the remaining regions of the Urals FD the correlation coefficient of the indicative functions is 0.99 (the Urals model group).

The Far-Eastern FD includes ten regions (Sakha Republic (Yakutia), Primorski Krai, Khabarovsk Territory, Amurskaya region, Kamchatka region, Koryak AD, Magadan region, Sakhalin region, Jewish AD, and Chukotski AD), the indicative functions of which are associated with a low correlation coefficient, 0.26. If only the coastal territories are left in this functional complex (the Far-Eastern model group), with the northern (Sakha Republic and Chukotski AD) and inland (Amurskaya region) excluded, then the connection of the individual functions of the remaining regions is enhanced dramatically $(r=0.68)$, which characterizes them as evolving under one-type economic-geographical conditions.

Since the Amurskaya region is unassociated functionally with the other regions of the FarEastern district, let us suppose that it is associated indicatively with the regions of the Siberian model group. Calculations lend credence to the fact that if the Amurskaya region is considered in the complex of the Siberian model group, then the correlation coefficient of the indicative functions of this group is high $(r=0.90)$. Hence it is substantiated mathematically that at the present time the socio-economic development potential of the Amurskaya region corresponds more closely in its local economic-geographical conditions to the Siberian regions of the RF rather than to the Far-Eastern regions, and the Amurskaya region can be incorporated in the Siberian model group.

The remaining regions (Khanty-Mansi, Yamalo-Nenetsky, Taimyr, Chukotka AD, and Sakha Republic) territorially represent the northern territories of Siberia and the Far East of Russia. Also, they unite into an independent functional complex referred arbitrarily to as the Northern-Siberian Far-Eastern model group $(r=0.85)$. The coefficients of the functions, and the correlation coefficients of the regional complexes of Russia's Federal Districts are presented in Table 2. The results from modeling the functional complexes are shown in italics.

Thus, eight model groups (functional complexes) of indicative functions have been identified in the composition of the RF (Table 2), some of which correspond to the boundaries of the existing administrative-territorial division into districts (Central, Northwestern, Southern and Volga FD), and the others forms new model groups (Urals, Siberian, Far-Eastern and Northern-Siberian Far-Eastern). Each functional complex is characterized by individual economic-geographical conditions of development, according to which the socio-economic potential of Russia's regions is realized.

Stage 3. The fractal schematic representation of the indicative function (2.2) (see Section 2, equations (2.2), (2.4), and (2.6)) is sued to consecutively calculate the coordinates of the centers of functional complexes of RF's regional model groups (see Table 2). For example, according to the calculations done for this purpose, the functional complex of the regions within the Siberian model group, the Far-Eastern model group and the Northern-Siberian Far-Eastern model group, respectively, is described by the equations $\bar{F}(a)=-1363.67 a_{1}-4847.70 a_{2}-572.14, \bar{F}(a)=$ $15137.44 a_{1}-522.60 a_{2}+2443.86$, and $\bar{F}(a)=4967.67 a_{1}-265.62 a_{2}-36802.03$. These functional complexes are arranged along the directrix $F_{2}(b)=-0.1240 b_{1}-0.4745 b_{2}-7378.9637$ (the correlation coefficient $r=0.73$ ) shown as a plane in Fig. 3.

This plane identifies in the general form the economic-geographical position of the Federal Districts of the RF or their model groups by the example of investments and the volume of industrial 


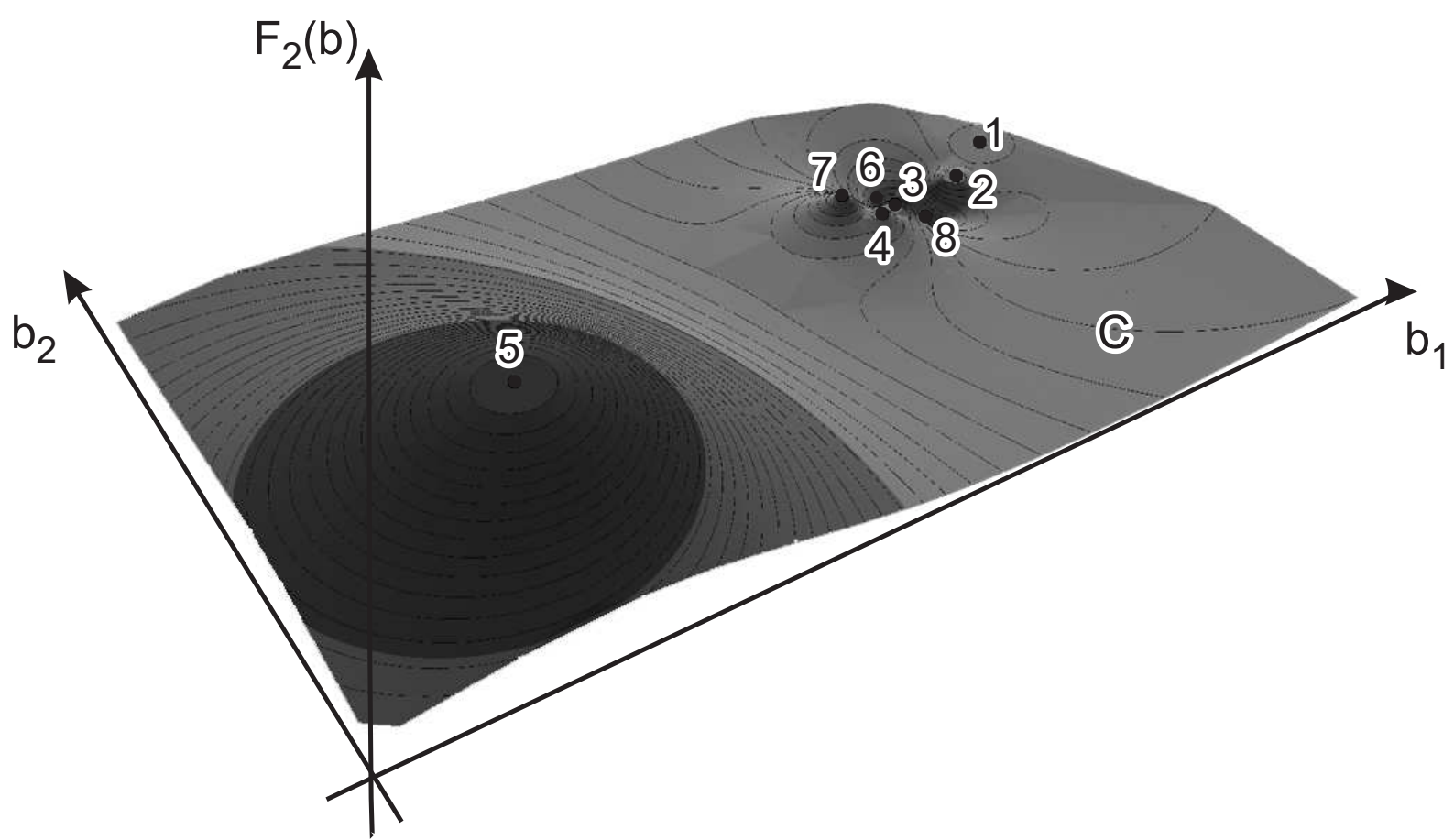

Figure 3: Schematic representation of the hierarchical fractal indicative model of the national economic system of the Russian Federation (for explanation, see the text)

and agricultural production. The coefficients of the centers of the functional complexes $\left(b_{1}, b_{2}, F_{2}\right)$ correspond to the consecutive number of a group (district) in Table 2. Besides, the figure highlights the directrix , showing the general tendency of the intra-state development of the RF for the period under investigation. The relief and direction of the directrix in this case shows a decline in the socio-economic development potential as regards "investments - volume of industrial production - volume of agricultural production" from the economic situation of the Urals model group (dark area of the plane) to the Central and Northwestern Federal Districts (unshaded area).

As a result, the mathematical equations obtained are used to generate a general hierarchical structure of an integral socio-economic space of situations $I(x)$ and economic-geographical conditions of territory development of Russia (Fig. 3), from the local (for the particular region) $I(x)$ (not shown in the figure) and regional (for several regions within the framework of federal districts and their model groups) $(\bar{F}(a)$, designated by numbers 1 to 8 in accordance with Table 2) to the national level (the directrix plane $F_{2}(b)$ ) and further to the inter-national and global level. Thus the pattern, provided in this paper, shows the general hierarchical socio-economic system of the RF in terms of the theory of the fractal indicative model outlined in this paper. 


\section{Conclusion}

The economic-mathematical model, developed in the form of a fractal multilevel indicative function (2.2), reflects appropriately and dramatically - through the use of calculated coefficients - the specific character of the region's socio-economic potential by the example of the connection of investments with the volumes of production. This model was used to identify the position of the Siberian regions in the system of inter-regional and national socio-economic ties and economicgeographical conditions of the conditions of development and generate a generalized hierarchical pattern of the national economic system of the Russian Federation in the "Investments-volumes of industrial and agricultural production" coordinate system. The indicative function, presented in this paper, offers a means of modeling the socio-economic development potential of the regions according to the initial invariant conditions of territory development - economic-geographical and socio-economic. As a result, the directrix plane (directrix) of the indicative function was constructed, which characterizes the changes in the socio-economic development potential of Russia's federal districts.

\section{References}

[1] V.G. Belomestnov. Management problems of economic potential of socio-economic systems. Probl. Sovrem. Ekonom., 1(2005), http://www.m-economy.ru/art.php3?artid=20651

[2] Yu.P. Ivanilov, A.V. Lotov. Mathematical models in economics. Nauka, Moscow, 1979.

[3] T.V. Inozemtseva. Management of the socio-economic development potential of rural municipal formations. Author's abstract of candidate of science (economics) degree dissertation. Manuscript, Izhevsk, 2006.

[4] L.I. Lopatnikov. Economic-mathematical dictionary: the dictionary of a modern economic science. Delo, Moscow, 2003.

[5] V.A. Snytko, S.B. Kuzmin, L.V. Danko, Eds. Geographical ideas and concepts as a tool for understanding the surrounding world. Institute of Geography SB RAS, Irkutsk, 2001.

[6] L.M. Korytny, A.N. Antipov, A.G. Aleshin, Eds. Geography: new methods and prospects of development. Institute of Geography SB RAS, Irkutsk, 2003.

[7] V.M. Chokan, E.A. Cherkashin, Eds. Scientific schools: a look into the future. Institute of Geography SB RAS, Irkutsk, 2005.

[8] L.M. Korytny, S.V. Ryashchenko, K.N. Misevich, Eds. Current problems in social geography. Institute of Geography SB RAS, Irkutsk, 2005.

[9] A.K. Cherkashin et al. Modeling of geographical systems. Institute of Geography SB RAS, Irkutsk, 2004. 
[10] P.Ya. Baklanov, L.M. Koritny, Eds. Geographical research in Siberia. Social geography. GEO, Novosibirsk, 2007.

[11] V. Leontiev, D. Ford. Intersectoral analysis of the effect of economic structure on environment. Ekonomika I Matematicheskiye Metody, 8(1972), No 3, 370-399.

[12] V.I. Gurman, Ed. Models of natural resource management. Nauka, Moscow, 1981.

[13] S.N. Vasiliev, Ed. Modeling and management of processes of regional development. Fizmatgiz, Moscow, 2001.

[14] V.I. Gurman, E.V. Ryumina, Eds. Modeling of the socio-ecologo-economic system of a region. Nauka, Moscow, 2001.

[15] B.A. Raizberg, L.Sh. Lozovsky, E.B. Starodubtseva. Modern economic dictionary. Infra-M, Moscow, 2000.

[16] J.W. Forrester. World Dynamics. Wright-Allen Press, Cambridge, 1971.

[17] E. Hansen. Economic cycles and national income. Publishing House of Foreign Literature, Moscow, 1959.

[18] A.K. Cherkashin. Polysystem analysis and synthesis. Applications in geography. Nauka, Novosibirsk, 1997.

[19] A.K. Cherkashin. Polysystem modeling. Nauka, Novosibirsk, 2005.

[20] L.S. Shakhovskaya, E.G. Popkova, E.G. Gushchina, Eds. Theory and methodology of research into the socio-economic potential of volgograd. VolgSTU, Volgograd, 2002.

[21] D.H. Meadows, Ed. The limits to growth. A report for the club of Rome's project on the predicament of mankind. Universe Books, N.Y., 1972. 
Table 1: The coefficients of indicative functions for the regions of the Siberian FD of the RF (1999-2002)

\begin{tabular}{|c|c|c|c|c|}
\hline Region & $\bar{F}(a)$ & $a 1$ & $a 2$ & $r$ \\
\hline Altai Republic & 241.1789 & 2.3410 & 0.0205 & 0.94 \\
\hline Republic of Buryatia & 845.3516 & 0.2476 & 0.3132 & 0.95 \\
\hline Republic of Tyva & 223.6299 & 0.1926 & 0.6340 & 0.94 \\
\hline Republic of Khakasia & -1016.4628 & 0.0249 & 0.2443 & 0.72 \\
\hline Altai Territory & -94.4526 & 0.3032 & -0.1335 & 0.97 \\
\hline $\begin{array}{l}\text { Krasnoyarsk Territory } \\
\text { (with districts) }\end{array}$ & 33569.7534 & -0.1084 & 3.8981 & 0.99 \\
\hline $\begin{array}{l}\text { Krasnoyarsk Territory } \\
\text { (without districts) }\end{array}$ & 27516.5900 & -0.0559 & 3.0836 & 0.98 \\
\hline $\begin{array}{l}\text { Taimyrsky (Dolgano- } \\
\text { Nenetsky) AD }\end{array}$ & 1166.2536 & 8.0757 & 29.0210 & 0.87 \\
\hline Evenki AD & -695.6346 & 7.8568 & -24.5186 & 0.97 \\
\hline $\begin{array}{l}\text { Irkutsk region (with } \\
\text { district) }\end{array}$ & 4568.9320 & 0.2518 & -0.5071 & 0.98 \\
\hline $\begin{array}{l}\text { Irkutsk region (with- } \\
\text { out district) }\end{array}$ & 4358.9553 & 0.2454 & -0.6158 & 0.98 \\
\hline $\begin{array}{l}\text { Ust-Ordynsky Buryat } \\
\text { AD }\end{array}$ & -33.1782 & -0.5466 & 0.1023 & 0.81 \\
\hline Kemerovo region & $\begin{array}{l}- \\
12029.6186\end{array}$ & 0.2269 & -1.8591 & 0.96 \\
\hline Novosibirsk region & 2077.6793 & 0.2400 & 0.1411 & 0.99 \\
\hline Omsk region & 1315.9233 & 0.3262 & -0.0991 & 0.95 \\
\hline Tomsk region & -3178.0721 & 0.5431 & -1.3692 & 0.99 \\
\hline $\begin{array}{l}\text { Chita region (with dis- } \\
\text { trict) }\end{array}$ & -2388.1415 & 0.6377 & -0.5309 & 0.61 \\
\hline $\begin{array}{l}\text { Chita region (without } \\
\text { district) }\end{array}$ & -857.9301 & 0.5042 & -0.0620 & 0.60 \\
\hline Aginsky Buryat AD & 362.7921 & 0.0306 & 0.8062 & 0.95 \\
\hline
\end{tabular}


Table 2: The coefficients of functional complexes of federal districts of the RF (1999-2002)

\begin{tabular}{|l|l|l|l|l|}
\hline Federal district & $F 2$ & $b 1$ & $b 2$ & $r$ \\
\hline 1. Central & -6279.8068 & 32789.2088 & 7865.5000 & 0.63 \\
\hline 2. Northeastern & -5022.2470 & 18603.4100 & -391.9331 & 0.64 \\
\hline 3. Southern & -4024.3313 & -2105.7398 & -5050.4722 & 0.76 \\
\hline 4. Volga & -375.4496 & -8953.5401 & -8021.4520 & 0.89 \\
\hline 5. Urals & - & 11367.3914 & -226.3790 & 0.79 \\
\hline $\begin{array}{l}\text { 5. Urals model group } \\
\text { (Kurgan, Sverdlovsk and } \\
\text { Chelyabinsk regions) }\end{array}$ & 27916.2885 & - & & \\
\hline 6. Siberian & -1576.1865 & 273.5437 & -111.5828 & 0.16 \\
\hline $\begin{array}{l}\text { 6. Siberian model group } \\
\text { (Altai Republic, Burya- } \\
\text { tia, Tyva, Khakassia, Alta } \\
\text { and Krasnoyarsk Terri- } \\
\text { tory, Amurskaya, Irkutsk, } \\
\text { Kemerovo, Novosibirsk, } \\
\text { Omsk, Tomsk, Tyumen } \\
\text { and Chita regions, Agin- } \\
\text { sky and Ust-Ordynsky } \\
\text { Buryat AD) }\end{array}$ & -572.1379 & -1363.6652 & -4847.6984 & 0.90 \\
\hline 7. Far-Eastern & -6991.2735 & 2855.0226 & 8.9776 & \\
\hline $\begin{array}{l}\text { 7. Far-Eastern model } \\
\text { group (Primorski and } \\
\text { Khabarovk Krai, Kam- } \\
\text { chatka, Magadan and } \\
\text { Sakhalin regions, Koryak } \\
\text { AD, Yewish AR). }\end{array}$ & 2443.8640 & - & & \\
\hline $\begin{array}{l}\text { 8.Northern-Siberian } \\
\text { Far-Eastern model group } \\
\text { (Khanty-Mansi, Yamalo- } \\
\text { Nenetsky AD, Taimyr, } \\
\text { Evenki and Chukotski } \\
\text { AD, Sakha Republic) }\end{array}$ & 36802.0316 & 15137.4358 & -522.5960 & 0.68 \\
\hline
\end{tabular}

